\title{
Quality of life (QOL) evaluation after acute coronary syndrome with simultaneous clopidogrel treatment
}

\author{
Jerzy Chudek ${ }^{1}$, Adam Kowalczyk², Anna Krystyna Kowalczyk ${ }^{3}$, Joanna Kwiatkowska4, \\ Grzegorz Raczak², Dariusz Kozłowski ${ }^{5}$
}

1Department of Pathophysiology, Medical University of Silesia, Katowice, Poland 2Department of Cardiology and Electrotherapy, Medical University of Gdansk, Gdansk, Poland

3Department of Public Health and Social Medicine, Medical University of Gdansk, Gdansk, Poland

${ }^{4}$ Department of Pediatric Cardiology and Congenital Heart Defect, Medical University of Gdansk, Poland

${ }^{5}$ Department of Public Health, Institute of Health Sciences, Pomeranian University of Słupsk, Słupsk, Poland

Submitted: 27 August 2011

Accepted: 10 October 2012

Arch Med Sci 2014; 10, 1: 33-38

DOI: 10.5114 /aoms.2013.38708

Copyright @ 2014 Termedia \& Banach

\section{Abstract}

Introduction: Double antiplatelet therapy with clopidogrel and acetylsalicylic acid is a standard procedure after acute coronary syndrome. This treatment carries a higher risk of complications. The main goal of this research was to assess the patients' quality of life after undergoing antiplatelet therapy with clopidogrel after acute coronary syndrome (ACS).

Material and methods: In the questionnaire research 3220 patients after ACS and treated with clopidogrel were included. The evaluation was carried out with the quality of life questionnaire SF-12.

Results: $37.9 \%$ of the interviewees experienced ACS-ST-elevation myocardial infarction (STEMI), 62.1\% non-ST-elevation myocardial Infarction (NSTEMI), on average within $23 \pm 42$ weeks ( $p<0.05$ ). $7.2 \%$ of the interviewees were receiving non-invasive treatment and in $2.4 \%$ cases it was fibrinolysis. $90.4 \%$ were treated with primary angioplasty and stenting. In $53.8 \%$ of cases a covered stent (DES) was implanted. $95.6 \%$ of the patients received, besides clopidogrel, acetylsalicylic acid. The lowest quality of life was observed after non-invasive treatment or fibrinolytic only $(p<0.05)$. The quality of life in those patients who underwent angioplasty and stent implantation was similar $(p<0.05)$. With time, a progressive improvement of all assessed quality of life aspects was observed $(p<0.05)$. The improvement was noted regardless of the ACS treatment method $(p<0.001)$. The differences between the patients were smaller at each successive evaluation $(p<0.05)$. In the case of vitality, emotional and psychic condition, they disappeared completely $(p<0.05)$.

Conclusions: The quality of life rises along with time passed after acute coronary syndrome. Invasive methods provide better quality of life than fibrinolysis and non-invasive treatment in the acute coronary syndrome patients.

Key words: acute coronary syndrome, quality of life, clopidogrel, coronary angioplasty, fibrinolysis.

\section{Introduction}

Acute coronary syndrome does not always require an invasive procedure. Even though in each case long-term treatment with an antiplatelet

\author{
Corresponding author: \\ Prof. Dariusz Kozłowski \\ Department of Cardiology \\ and Electrotherapy \\ Medical University of Gdansk \\ 7 Debinki St \\ 80-211 Gdansk, Poland \\ E-mail: dkozl@gumed.edu.pl
}


drug is necessary, in the case of non-invasive management only acetylsalicylic acid with clopidogrel administration for at least 12 months is recommended [1]. An invasive procedure such as angioplasty combined with stent implantation (revascularisation) is nowadays the most common method. Stent implantations have lowered the restenosis occurrence in the first 6 to 9 months from 39.\% to 23.9\% [2]. Unfortunately, regular stent (BMS) implantation, or even a covered one (DES), is correlated with the stent thrombosis risk [3, 4]. That is why double antiplatelet therapy (acetylsalicylic acid with clopidogrel) is necessary after the procedure [5]. The cardiological standards describe this kind of treatment as obligatory for the first month after bare metal stent (BMS) implantation and for at least 12 months after a covered one (DES) [6].

Stable angina patients' optimal non-invasive treatment limits stenocardial complaints and allows the quality of life to improve [7]. The COURAGE research showed that stable angina patients after transcutaneous balloon angioplasty with stent implantation combined with optimal pharmacotherapy have insignificant improvement in the quality of life. The differences disappear after 24 months [8]. The invasive procedure provides no prognosis benefit [5], though early transcutaneous revascularization correlated with the improvement of 1 year survival rate and the quality of life [9].

No research comparing the quality of life after acute coronary syndrome depending on the antiplatelet treatment has been conducted so far. Antiplatelet treatment carries a higher risk of bleeding, especially from the nose, and is a common cause of bruising [10]. These complications may limit the patient's physical activity. In the present research, in order to evaluate the quality of life, the SF-12 form, which is a shortened version of the SF-36 form, was used. The SF-36 form was created in the second half of the 1980s as part of the Medical Outcomes Study (MOS). Both forms assess eight dimensions of physical, social and individual function as well as the personal sense of mental health, vitality and general health, pain levels and feeling of discomfort. The SF-36 form was validated by the Psychiatry and Neurology Institute in Warsaw in the late 1990s [11]

The evaluation of patients' quality of life after using antiplatelet therapy with clopidogrel after suffering acute coronary syndrome

\section{Material and methods}

Three hundred and twenty-one doctors took part in the research: 130 internal medicine specialists, 101 cardiologists and 90 general practitioners supervising the acute coronary syndrome patients' management. Three thousand two thousand and twenty patients after acute coronary syndrome (ACS) and treated with clopidogrel, in the past or at pres- ent, were included in this research. The only research inclusion criterion was clopidogrel treatment after ACS; there were no exclusion criteria. The study was approved by an Ethics committee.

The questionnaire included the following data: demographic (gender, age, place of residence, level of education), anthropometric (body mass, height), blood pressure measurement, the history concerning smoking before ACS and at present, the characteristics of ACS (type, treatment, implanted stent type), information about antiplatelet management after ACS, concomitant diseases (arterial hypertension, diabetes mellitus, hepatic cirrhosis, gastrointestinal ulceration, asthma and chronic obturative pulmonary disease, lower limbs atherosclerosis, benign prostatic hyperplasia, chronic renal disease, gout), cardiological drugs used. The second part of the questionnaire consisted of questions included in the health and wellbeing SF-12v form certified with a Quality Metric Incorporated licence (no. CT119837/OP005421).

During the next two visits, at 2-month intervals, any hospitalizations, revascularization procedures, or changes in antiplatelet therapy, including the reasons for clopidogrel treatment termination and current cardiological pharmacotherapy, along with the quality of life, were reported on the SF-12v form. Based on the body mass and height the body mass index (BMI) was calculated. According to commonly accepted criteria the overweight were classified as $25-30 \mathrm{~kg} / \mathrm{m}^{2}$ and obese as $\geq 30 \mathrm{~kg} / \mathrm{m}^{2}$.

The raw results of the SF-12v form answers were recalculated to the percentage values according to the highest and the lowest values observed in the investigated population. The transformations were done with the formula: (outcome value - the lowest value in the population)/scale range $\times 100 \%$.

The analysis of the place of residence, level of education, alimentation condition, concomitant diseases, types of ACS, administered treatment, and types and quantity of implanted stents in particular patients was performed. The quality of life analysis was done independently for patients treated non-invasively, with fibrinolysis and treated with angioplasty or angioplasty with stent implantation.

The primary planned analysis of the quality of life after the antiplatelet treatment was withdrawn, because all the patients received clopidogrel initially and the group that stopped clopidogrel administration during the follow-up was small (4.7\%).

\section{Statistical analysis}

The statistical analysis was done using Statistica 8.0 PL software. The analysis outcome was presented as a proportion or average with standard variations. To compare the variables the ANOVA test and Tukey's test were run. The value $p<0.05$ was 
accepted as significant. The results have been presented in the tables and diagrams.

\section{Results}

\section{Description of the investigated group}

The investigated group treated with clopidogrel after acute coronary syndrome consisted of 3220 patients: 2002 men and 1218 women. According to GUS (main Polish statistical office) data the overrepresentation of city dwellers (81.6\%) and people with high education level (27.1\%) was observed. $29.1 \%$ of those questioned were obese. $18.3 \%$ were active smokers, even though before ACS as many as $54.8 \%$ were smokers. After the ACS event $66.8 \%$ of men and $73 \%$ of women who took part in the research quit smoking.

$37.9 \%$ of interviewees experienced ACS type STelevation myocardial infarction (STEMI) and 62.1\% non-ST-elevation myocardial infarction (NSTEMI). $7.2 \%$ of patients were treated non-invasively, while $2.4 \%$ of the patients were administered only fibrinolysis. $90.4 \%$ of the patients underwent an invasive procedure, most commonly primary angioplasty with stenting. In $53.8 \%$ of the cases a covered stent (DES) was implanted. Time that passed from ACS was on average $23 \pm 42$ weeks.

Concomitant diseases were reported in $95.7 \%$ of cases. Arterial hypertension was diagnosed in $88.4 \%$ of interviewees, diabetes mellitus in 38\%. Gastroduodenal ulceration was reported in $13.8 \%$ of cases. $11.9 \%$ of the patients suffered from chronic obturative pulmonary disease (COPD) or asthma. 23.8\% of men were diagnosed with benign prostate hyperplasia.

$88.1 \%$ of those questioned were receiving $\beta$-adrenolytics, including 282 with chronic bronchial diseases (75.4\%). 95.1\% of the patients did not take any drug that inhibits renin-angiotensin system activity. Diuretics were taken by $46.0 \%$ of the interviewees, statins by $90.4 \%$ and fibrates by $7.0 \% .4 .7 \%$ received combined hypolipidaemic treatment (Table I).

\section{Antiplatelet therapy}

Most commonly (98.5\%) the clopidogrel dosage was $75 \mathrm{mg}$ per day. A higher dosage was received by $1.5 \%$ of those questioned. $96.5 \%$ received simultaneously acetylsalicylic acid, most frequently (78.3\%) $75 \mathrm{mg} /$ day. Moreover, $2.5 \%$ of interviewees were receiving ticlopidine ( $11.3 \%$ not receiving and $0.9 \%$ receiving acetylsalicylic acid).

$2.9 \%$ of the patients were treated with orally administered anticoagulation (acenocoumarol or warfarin) and $0.4 \%$ with low molecular weight heparin.

\section{Quality of life}

Overall, the general health aspect was the worst when appraised by the interviewees. Women, in
Table I. Concomitant medicaments used in the investigated group after acute coronary syndrome $(n=3.220)$

\begin{tabular}{|c|c|}
\hline Medicament & $N(\%)$ \\
\hline Clopidogrel & $3220(100)$ \\
\hline 75 mg/day & $3172(98.5)$ \\
\hline $150 \mathrm{mg} /$ day & $35(1.1)$ \\
\hline 300 mg/day & $13(0.4)$ \\
\hline Acetylsalicylic acid & $3078(95.6)$ \\
\hline 30 mg/day & $2(0.1)$ \\
\hline 75 mg/day & $2522(78.3)$ \\
\hline 100 mg/day & $84(2.6)$ \\
\hline 150 mg/day & $451(14.0)$ \\
\hline 300 mg/day & $19(0.6)$ \\
\hline Ticlopidine & $80(2.5)$ \\
\hline 250 mg/day & $42(1.3)$ \\
\hline 500 mg/day & $38(1.2)$ \\
\hline Anticoagulants & $93(2.9)$ \\
\hline LMW heparin & $14(0.4)$ \\
\hline \multicolumn{2}{|l|}{ Cardiological medicament } \\
\hline ACE inhibitors & $2670(82.9)$ \\
\hline Sartans & $757(23.5)$ \\
\hline$\beta$-Adrenolytics & $2836(88.1)$ \\
\hline Diuretics & $1482(46.0)$ \\
\hline Nitrates & 509 (15.8) \\
\hline $\mathrm{Ca}^{2+}$ channel blockers & $762(23.7)$ \\
\hline \multicolumn{2}{|l|}{ Hypolipaemic medicament } \\
\hline Statins & $2911(90.4)$ \\
\hline Fibrates & $226(7.0)$ \\
\hline
\end{tabular}

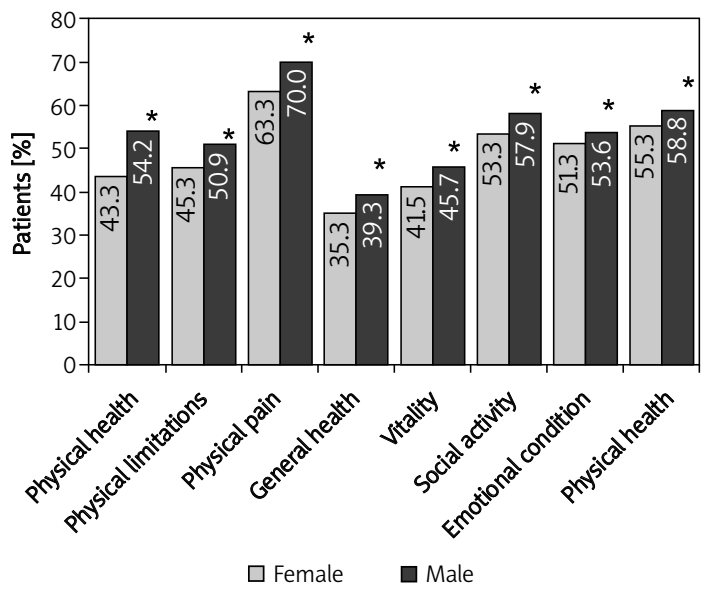

Figure 1. Quality of life comparison between males and females after acute coronary syndrome assessed during the first visit ${ }^{*} p<0.001$ 
Table II. Quality of life assessment during three consecutive outpatient visits after acute coronary syndrome depending on the ACS management strategy

\begin{tabular}{|c|c|c|c|c|c|}
\hline Variable & Visit no. & $\begin{array}{c}\text { Non-invasive } \\
(n=232)\end{array}$ & $\begin{array}{l}\text { Fibrinolysis } \\
\quad(n=78)\end{array}$ & $\begin{array}{l}\text { Angioplasty } \\
(n=230)\end{array}$ & $\begin{array}{c}\text { Stenting } \\
(n=2680)\end{array}$ \\
\hline \multirow[t]{3}{*}{ Physical health [\%] } & 1 & $34.7 \pm 27.7$ & $39.1 \pm 25.4$ & $51.5 \pm 25.9$ & $51.6 \pm 30.3$ \\
\hline & 2 & $45.8 \pm 28.7$ & $48.7 \pm 22.8$ & $55.0 \pm 24.9$ & $60.2 \pm 27.6$ \\
\hline & 3 & $52.8 \pm 31.3$ & $57.7 \pm 28.6$ & $60.4 \pm 24.0$ & $65.8 \pm 26.3$ \\
\hline \multirow[t]{3}{*}{ Physical limitations [\%] } & 1 & $39.7 \pm 12.1$ & $42.3 \pm 17.5$ & $50.2 \pm 21.0$ & $49.6 \pm 22.3$ \\
\hline & 2 & $49.1 \pm 20.1$ & $51.3 \pm 19.7$ & $54.9 \pm 19.5$ & $57.5 \pm 21.0$ \\
\hline & 3 & $55.4 \pm 23.1$ & $59.3 \pm 19.7$ & $60.5 \pm 20.4$ & $62.4 \pm 20.7$ \\
\hline \multirow[t]{3}{*}{ Physical pain [\%] } & 1 & $57.3 \pm 24.6$ & $56.4 \pm 24.0$ & $65.4 \pm 25.9$ & $68.8 \pm 25.9$ \\
\hline & 2 & $63.7 \pm 23.6$ & $65.4 \pm 21.8$ & $69.5 \pm 23.4$ & $75.2 \pm 22.9$ \\
\hline & 3 & $71.3 \pm 23.9$ & $71.2 \pm 21.7$ & $75.4 \pm 22.1$ & $78.6 \pm 21.3$ \\
\hline \multirow[t]{3}{*}{ General health [\%] } & 1 & $33.0 \pm 18.8$ & $27.6 \pm 12.5$ & $40.2 \pm 16.7$ & $38.2 \pm 18.8$ \\
\hline & 2 & $38.7 \pm 19.1$ & $39.1 \pm 17.8$ & $42.3 \pm 15.6$ & $44.3 \pm 18.0$ \\
\hline & 3 & $44.6 \pm 24.0$ & $41.7 \pm 17.4$ & $47.3 \pm 16.1$ & $49.2 \pm 18.2$ \\
\hline \multirow[t]{3}{*}{ Vitality [\%] } & 1 & $39.7 \pm 24.0$ & $36.5 \pm 18.8$ & $46.1 \pm 23.0$ & $44.6 \pm 23.9$ \\
\hline & 2 & $48.2 \pm 24.7$ & $47.4 \pm 21.2$ & $50.2 \pm 21.9$ & $51.3 \pm 22.9$ \\
\hline & 3 & $53.5 \pm 26.0$ & $52.6 \pm 20.4$ & $53.8 \pm 22.4$ & $55.7 \pm 22.8$ \\
\hline \multirow[t]{3}{*}{ Social activity [\%] } & 1 & $50.9 \pm 22.3$ & $50.6 \pm 23.1$ & $56.7 \pm 23.2$ & $56.7 \pm 24.6$ \\
\hline & 2 & $56.9 \pm 23.6$ & $56.4 \pm 19.5$ & $62.7 \pm 20.0$ & $64.7 \pm 22.9$ \\
\hline & 3 & $63.3 \pm 27.9$ & $67.9 \pm 18.0$ & $65.7 \pm 21.4$ & $69.3 \pm 22.5$ \\
\hline \multirow[t]{3}{*}{ Emotional condition [\%] } & 1 & $48.6 \pm 16.7$ & $45.5 \pm 13.8$ & $52.0 \pm 16.4$ & $53.3 \pm 18.2$ \\
\hline & 2 & $56.9 \pm 21.5$ & $54.2 \pm 19.6$ & $60.4 \pm 19.5$ & $62.2 \pm 21.2$ \\
\hline & 3 & $61.4 \pm 23.6$ & $61.2 \pm 20.1$ & $64.0 \pm 21.0$ & $66.2 \pm 20.7$ \\
\hline \multirow[t]{3}{*}{ Psychic health [\%] } & 1 & $53.4 \pm 19.2$ & $49.7 \pm 17.7$ & $57.7 \pm 18.3$ & $58.0 \pm 20.1$ \\
\hline & 2 & $61.3 \pm 19.9$ & $61.5 \pm 16.7$ & $62.3 \pm 16.8$ & $64.4 \pm 18.6$ \\
\hline & 3 & $64.3 \pm 21.8$ & $66.7 \pm 17.4$ & $66.5 \pm 17.3$ & $68.1 \pm 17.9$ \\
\hline
\end{tabular}

Statistical variability $p<0.05$

comparison to men, claimed lower quality of life in all health aspects according to the SF-12 form (Figure 1). The biggest difference in appraisal regarded physical health. Patients aged 60 years or older described their quality of life as the lowest. The level of education as well as where the patients lived were also contributing factors. The highest quality of life was observed among patients with higher education. Lower quality of life, lower social activity, limitations in physical activity, high levels of pain, and shorter longevity were observed among the city residents.

The lowest quality of life was claimed by patients whose ACS treatment was limited to non-invasive management or fibrinolysis (Table II). Non-invasive methods were more often offered to patients over 70 years old. The quality of life after angioplasty and stent implantation was similar. The biggest differences regarded the physical health aspect. Concomitant diseases such as diabetes mellitus, chronic obstructive pulmonary disease (COPD), asthma, lower limbs atherosclerosis, chronic renal disease and gout were among the high-impact factors.

\section{Management adherence}

Three thousand one hundred and eighty-two (98.8\%) patients reported to the first outpatient follow-up, 3102 (96.3\%) to the following one. During the period of time in which the research was conducted, 18 patients died (0.6\%), while the condition of $53(3.6 \%)$ is unknown.

The medical recommendations level of compliance for clopidogrel was $95.3 \%$ and was similar to adherence of acetylsalicylic acid. High adherence was noted for angiotensin convertase inhibitors (97.4\%), $\beta$-adrenolytics (94.8\%) and statins $(97.5 \%)$.

\section{Quality of life changes}

As time progressed an improvement of all assessed aspects of life was observed regardless of 
Table III. Life quality after acute coronary syndrome

\begin{tabular}{|lccc|}
\hline Variable & First visit $(n=3220)$ & Second visit $(n=3182)$ & Third visit $(n=3102)$ \\
\hline Physical health [\%] & $50.1 \pm 30.5$ & $58.5 \pm 27.7^{\wedge}$ & $64.3^{\wedge} \pm 26.8^{\wedge}$ \\
\hline Physical limitations [\%] & $48.8 \pm 22.2$ & $56.5 \pm 20.9^{\wedge}$ & $61.7^{\wedge} \pm 20.9^{\wedge}$ \\
\hline Physical pain [\%] & $67.5 \pm 26.0$ & $73.8 \pm 23.2^{\wedge}$ & $77.7 \pm 21.7^{\wedge}$ \\
\hline General health [\%] & $37.7 \pm 18.6$ & $43.6 \pm 18.0^{\wedge}$ & $48.5^{\wedge} \pm 18.5^{\wedge}$ \\
\hline Vitality [\%] & $44.1 \pm 23.8$ & $50.9 \pm 22.9^{\wedge}$ & $55.3 \pm 21.9^{\wedge}$ \\
\hline Social activity [\%] & $56.1 \pm 24.4$ & $63.8 \pm 22.7^{\wedge}$ & $68.6 \pm 22.7^{\wedge}$ \\
\hline Emotional condition [\%] & $52.7 \pm 17.9$ & $61.5 \pm 21.1^{\wedge}$ & $65.6 \pm 21.0^{\wedge}$ \\
\hline Psychic health [\%] & $57.5 \pm 19.9$ & $63.9 \pm 18.5^{\wedge}$ & $67.7 \pm 18.1^{\wedge}$ \\
\hline
\end{tabular}

Statistical difference vs. first visit $\wedge p<0.001$

the ACS treatment method (Table III). The differences between the patients treated non-invasively, with fibrinolysis and invasively were smaller at successive evaluations. Vitality, emotional state and mental health differences disappeared completely.

\section{Discussion}

The present research proved that non-invasive and fibrinolytic ACS treatment correlated with worse quality of life in comparison with invasive ACS treatment. The perception of worsened quality of life became smaller with the time that passed after the procedure.

Coronary artery angioplasty procedures in acute myocardial infarction patients increase the survival rate, limit the heart muscle necrosis range and enable better left ventricular performance [12]. In the evaluated patients' group primary transcutaneous angioplasty was done in $89.1 \%$ of cases. Early coronary vessels recanalisation provides great benefits; hence the quality of life assessment was not the researchers' focus in that particular case.

The present research shows that the above procedures improve various aspects of life. It means that the ACS patient quality of life depends on the time necessary to report to the doctor and availability of the interventional cardiology centre. If a patient reports late (after 8-12 $\mathrm{h}$ following the stenocardial complaints) it minimizes his/her chances of primary revascularisation and worsens the prognosis and, consequently, the quality of life.

The quality of life depends on many factors such as gender, age, level of education, place of residence and concomitant diseases. The latest published research results point out the patients' age as a significant factor affecting the quality of life after ACS. That research shows that patients over 80 years old benefit the most from this procedure. Nevertheless, as patients get older they are less frequently qualified to receive a primary revascularization procedure. In this research stent implantation was performed on a considerably high percentage (64.8\%) over 80 years old [13].

None of the aforementioned factors could influence the self-assessment improvement observed with passage of time. It can be presumed that the improvement of the quality of life may be a result of the time that passed after the procedure $[14,15]$. With time the anticipation of an ACS recurrence declines, with consequences not only for psychological aspects, but also for physical ones [16].

This research has got multiple limitations. The evaluation of the quality of life was performed at different time intervals after ACS, which caused significant group heterogeneity. It should be presumed that the choice of the group was determined by the clinical condition, and that patient groups may not be comparable. The research does not allow assessment of the influence of clopidogrel single treatment on the quality of life, because all trial members followed a treatment scheme based on this medication. The only difference was the administration time interval. However, finding adequately numerous groups of patients intolerant to clopidogrel is extremely difficult when the medication is well tolerated.

In conclusion, the quality of life improves with time after suffering from the acute coronary syndrome. Invasive methods provide better quality of life than fibrinolysis and non-invasive treatment in acute coronary syndrome patients.

\section{References}

1. Bassand JP, Hamm CW, Ardissino D, et Al. Guidelines for the diagnosis and treatment of non-ST-segment elevation acute coronary syndromes. Eur Heart J 2007; 28: 1598-660.

2. Svilaas T, van der Horst IC, Zijlstra F. A quantitative estimate of bare-metal stenting compared with balloon angioplasty in patients with acute myocardial infarction: angiographic measures in relation to clinical outcome. Heart 2007; 93: 792-800.

3. Brar SS, Leon MB, Stone GW, et al. Use of drug-eluting stents in acute myocardial infarction: a systematic review and metaanalysis. J Am Coll Cardiol 2009; 53: 1677-89. 
4. Lee SW, Park SW, Hong MK, et al. Triple versus dual antiplatelet therapy after coronary stenting - impact on stent thrombosis. J Am Coll Cardiol 2005; 46: 1833-7.

5. Daemen J, Wenaweser P, Tsuchida K, et al. Early and late coronary stent thrombosis of sirolimus-eluting and paclitaxel-eluting stents in routine clinical practice: data from a large two-institutional cohort study. Lancet 2007; 369: 667-78

6. Van de Werf F, Bax J, Betriu A, et al. Management of acute myocardial infarction in patients presenting with persistent ST-segment elevation. The Task Force on the management of ST-segment elevation acute myocardial infarction of the European Society of Cardiology. Eur Heart J 2008; 29: 2909-45.

7. Weintraub WS, Spertus JA, Kolm P, et al COURAGE Trial Research Group. Effect of $\mathrm{PCl}$ on quality of life in patients with stable coronary disease. N Engl J Med 2008; 359: 677-87.

8. Boden WE, O'Rourke RA, Teo KK, et al.; the COURAGE Trial Research Group. Optimal medical therapy with or without PCI for stable coronary disease. N Engl J Med 2007; 356: 1503-16.

9. Sleeper LA, Ramanathan K, Picard MH, et Al.; SHOCK Investigators. Functional status and quality of life after emergency revascularization for cardiogenic shock complicating acute myocardial infarction. J Am Coll Cardiol 2005; 46: 266-73.

10. Mehta SR, Bassand JP, Chrolavicius S, et al. Design and rationale of CURRENT-OASIS 7: a randomized, $2 \times 2 \mathrm{fac}$ torial trial evaluating optimal dosing strategies for clopidogrel and aspirin in patients with ST and non-STelevation acute coronary syndromes managed with an early invasive strategy'. Am Heart J 2008; 156: 1080-8.

11. Jarema M, Bury R, Konieczynska B, et al. Comparison of patients life quality assessment managed with different forms of psychiatric care. Psychiatr Pol 1997; 31: 585-94.

12. The Task Force on Myocardial Revascularization of the European Society of Cardiology (ESC) and the European Association for Cardio-Thoracic Surgery (EACTS). Practical guidelines - Guidelines on myocardial revascularization, 2010.

13. Li R, Yan BP, Dong M, et al. Quality of life after percutaneous coronary intervention in the elderly with acute coronary syndrome. Int J Cardiol 2012; 155: 90-6.

14. Cichocka-Jarosz E, Brzyski P, Świebocka E, et. al. Healthrelated quality of life in Polish adolescents with Hymenoptera venom allergy treated with venom immunotherapy. Arch Med Sci 2012; 8: 1076-82.

15. Ulubay G, Sarinc Ulasli S, Savas Bozbas S, et al. Effects of peripheral neuropathy on exercise capacity and quality of life in patients with chronic obstructive pulmonary diseases. Arch Med Sci 2012; 8: 296-302.

16. Baczyk G, Opala T, Kleka P. Quality of life in postmenopausal women with reduced bone mineral density: psychometric evaluation of the Polish version of QUALEFFO-41. Arch Med Sci 2011; 7: 476-85. 